\title{
Pollution feature analysis on heavy metals in rainfall runoff of Qingdao residential area
}

\author{
Chunrong ZHANG ${ }^{1}$, Chunjin ZHANG ${ }^{1}$, Zongjun $\mathrm{GAO}^{1}$, Zhenglong WU ${ }^{1}$ \\ ${ }^{1}$ Shandong University of Science and Technology
}

KEYWORD: rainfall runoff; heavy metals; first flushing effect; event mean concentrations; correlation

ABSTRACT: Based on the 45 rainfall runoff samples that are collected from Qingdao residential area after the raining of July 22, 2014 and September 28, 2014, this paper tests the contents of heavy metals $\mathrm{Cd}, \mathrm{Cu}, \mathrm{Pb}, \mathrm{Zn}$ and $\mathrm{Mn}$. And based on the test results, this paper further analyzes event mean concentration (abbr. EMC), first flushing effect, and the correlation of these heavy metals. Experimental results show that the EMC of most of heavy metals are in low level, expect for the one of Cd collected on September 28, 2014. Therefore, the quality of most rainfall runoff samples is good. The first flushing effect of heavy metals in rainfall runoff of July 22, 2014 is obvious. In contrast, the first flushing effect does not appear in the rainfall runoff of September 28, 2014. The correlation between $\mathrm{Cu}, \mathrm{Pb}$, and $\mathrm{Zn}$ in rainfall runoff is strong, while the one between $\mathrm{Cd}, \mathrm{Mn}$ and other heavy metals are weak.

With the development of economy, the discharge of industry and domestic pollutant in city increase rapidly. All these kinds of pollutants are flushed into rivers and lakes with the rainfall runoff. Especially, the heavy metals are carried into the rivers and lakes. As all of the heavy metals are difficult to decompose and transform, they will persist in the waters for very long time. After accumulating to some extent, these heavy metals will poison water bodies. Once the polluted water bodies are eaten by human, human body and life safety will be endangered ${ }^{[1,2]}$. As early as $70 \mathrm{~s}$ in last century, abroad researchers have begun study the pollution of heavy metals in rainfall runoff ${ }^{[3,}$ ${ }^{4]}$. In contrast, the researches in our country start relatively late. Related literatures mainly focus on the analysis about the features of pollution about rainfall runoff of the urban road in recent years ${ }^{[5}$, ${ }^{6,7]}$. No literatures are found about the similar research in residential area. The aim of this paper is study the EMC, first flushing effect, and correlations of the heavy metals in the rainfall runoff of Qingdao residential area, thus provide scientific basis for controlling of rainfall runoff pollution of heavy metals and development and utilization of water resources.

\section{METHOD}

\section{Sampling sites and methods}

In the research of this paper, we select the low-lying areas of the Licun College Road residents in Qingdao district as the sampling points. The samples are collected on July 22, 2014 and September 28,2014 , after raining. The rain on July 22, 2014 is high intensity showers. At the start of rainfall runoff, we collected samples using $500 \mathrm{ml}$ pure water bottles, which have been cleaned by acid. The collection interval is 1 to 2 minutes. In addition, 24 samples are collected. The rain on September 28,2014 is light rain at the beginning and moderate rain lately. At the beginning of rain, 6 samples are collected by similar method. The only difference is that these 6 samples are collected by intervals of 5-8 minutes. In the later period of rain, 15 samples are collected by intervals of 3-5 minutes. Therefore, totally 21 samples are collected on September 28, 2014. 


\section{Measurement of samples}

In experiments, glass wares are made of high borosilicate glass. Before using, all these wares are soaked in HNO3 (concentration is $10 \%$ ) for 24 hours or more, and then wash them with water, and finally rinse 3 times using deionized water. To measure the content of heavy metals in rainfall runoff, excellent level of GR nitrate is put into each sample after it is collected. That aims at adapting the $\mathrm{pH}$ of samples to the value of 1-2. The content of $\mathrm{Cd}, \mathrm{Cu}, \mathrm{Pb}$ and $\mathrm{Zn}$ are measured using TAS-990 atomic absorption spectrophotometer under the instruction of water quality-Determination of copper, zinc, lead and cadmium-Atomlc absorption spectrometry ${ }^{[8]}$. And the content of $\mathrm{Mn}$ is measured by TU-1810 ultraviolet visible spectrophotometer under the introduction of water quality-Determination of manganese-Potassium periodate spectrophotometric method ${ }^{[9]}$. To ensure the reliability and validity of the results, this study used the method of repeated sample analysis. This method can ensure the accuracy of analysis data about water quality. All the data analysis of this paper is run in EXCEL and SPSS software.

\section{RESULTS AND DISCUSSIONS}

\section{EMC of heavy metals in rainfall runoff}

Because of the large difference between the concentrations of various pollutants in a rainfall, U.S. Environmental Protection Agency published the results of the nationwide urban runoff program and suggest that pollutant load of sessional rainfall runoff should be quantified by EMC ${ }^{[10]}$. The calculation method is defined in formula (1).

$$
E M C=\bar{C}=\frac{M}{V}=\frac{\int_{0}^{t_{r}} c(t) q(t) d t}{\int_{0}^{t_{r}} q(t) d(t)}
$$

where $M$ is the total amount of heavy metals during the rainfall runoff (unit of measurement is $\mathrm{mg}$ ), $\mathrm{V}$ is the total runoff (unit of measurement is $\mathrm{L}$ ), $\mathrm{t}$ is the moment when samples are collected, $\mathrm{c}(\mathrm{t}$ ) represents the concentration $\left(\mathrm{mg} \cdot \mathrm{L}^{-1}\right)$ of heavy metals in the moment of $t, q(t)$ is the water flow $\left(\mathrm{L} \cdot \mathrm{min}^{-1}\right)$ of in the moment of $\mathrm{t}$, tr is the total duration(min) of runoff.

Table 1 shows the comparison between the heavy metal analysis results we get in Qingdao residential area

\begin{tabular}{|c|c|c|c|c|c|}
\hline \multirow{2}{*}{$\begin{array}{l}\text { Heavy } \\
\text { metal }\end{array}$} & \multirow{2}{*}{$\begin{array}{l}\text { July } \\
22, \\
2014 \\
\end{array}$} & \multirow{2}{*}{$\begin{array}{l}\text { Septemb } \\
\text { er } \\
28,2014\end{array}$} & \multicolumn{3}{|c|}{ GB3838-2002 } \\
\hline & & & III & IV & V \\
\hline $\begin{array}{l}\mathrm{Cd}(\mathrm{mg} / \\
\text { 1) }\end{array}$ & 0.001 & 0.601 & $\begin{array}{l}0.00 \\
5\end{array}$ & 0.005 & 0.01 \\
\hline $\begin{array}{l}\mathrm{Cu}(\mathrm{mg} / \\
\text { 1) }\end{array}$ & 0.024 & 0.076 & 1 & 1 & 1 \\
\hline $\mathrm{Pb}(\mathrm{mg} / 1$ & 0.003 & 0.003 & 0.05 & 0.05 & 0.1 \\
\hline $\begin{array}{l}\mathrm{Zn}(\mathrm{mg} / \\
1)\end{array}$ & 0.229 & 0.14 & 1 & 2 & 2 \\
\hline $\begin{array}{l}\mathrm{Mn}(\mathrm{mg} \\
/ \mathrm{l})\end{array}$ & 0.237 & 0.291 & & & \\
\hline
\end{tabular}


According to the second column of table 1, we can see that the pollution load EMC of heavy metals in rainfall runoff samples collected on date July 22, 2014 is small, and even less than the standard of surface water category III. Therefore, we can conclude that the quality of the water in the collected area is good. Comparatively, according to the third column of table 1, the pollution load EMC of Cd in rainfall runoff samples collected on date September 28, 2014 is larger than the standard of surface water category $\mathrm{V}$. Therefore, the water quality is poor so that need to be controlled. The EMC of $\mathrm{Cu}, \mathrm{Pb}, \mathrm{Zn}$ in rainfall runoff samples are small, which is smaller than the standard of surface water category III. Therefore, we can conclude that the water quality is quite good. Besides, surface water environmental quality standard GB3838-2002 does not specify the content of metal $\mathrm{Mn}$. However, according to research, if there is a large amount of $\mathrm{Mn}$ in the water body, the water body is easily to be black ${ }^{[11]}$. Therefore, $\mathrm{Mn}$ is also a heavy metal pollutant in rainfall runoff.

\section{First flushing effect of heavy metals in rainfall runoff}

First flushing effect means that, in the initial stage of rainfall runoff, a pollutant concentration reaches a high peak. A large amount of pollutants discharged into the receiving water body, which seriously threaten the water environment in city. First flushing effect normally depends on the dimensionless normalized cumulative mass and volume, i.e., runoff curve, where longitudinal coordinate represents the dimensionless cumulative pollutant load fraction (denoted as $\mathrm{m}^{\prime}(\mathrm{t})$ ) and horizontal coordinate is dimensionless cumulative runoff volume fraction (denoted as $v^{\prime}(t)$ ). The calculation method of $m^{\prime}(t)$ and $v^{\prime}(t)$ is defined in formulas $(2)$ and $(3)^{[12,13]}$.

$$
m^{\prime}(t)=\frac{m(t)}{M}=\frac{\int_{0}^{t} c(t) q(t) d t}{\int_{0}^{t_{r}} c(t) q(t) d(t)}
$$

$v^{\prime}(t)=\frac{v(t)}{V}=\frac{\int_{0}^{t} q(t) d t}{\int_{0}^{t_{r}} q(t) d(t)}$

where $m(t)$ is the accumulated quality of heavy metal in rainfall runoff during t moment, $v(t)$ is the accumulated volume of rainfall runoff during $t$ moment, $M$ is the total amount of heavy metals during the rainfall runoff (unit of measurement is $\mathrm{mg}$ ), $\mathrm{V}$ is the total runoff (unit of measurement is $\mathrm{L}), \mathrm{t}$ is the moment when samples are collected, $\mathrm{c}(\mathrm{t})$ represents the concentration $\left(\mathrm{mg} \cdot \mathrm{L}^{-1}\right)$ of heavy metals in the moment of $\mathrm{t}, \mathrm{q}(\mathrm{t})$ is the water flow $\left(\mathrm{L} \cdot \mathrm{min}^{-1}\right)$ of in the moment of $\mathrm{t}$, tr is the total duration(min) of runoff.

Taking dimensionless cumulative runoff volume fraction $v^{\prime}(t)$ as horizontal coordinate, and the dimensionless cumulative pollutant load fraction $\mathrm{m}^{\prime}(\mathrm{t})$ as longitudinal coordinate, we draw the cumulative load fraction - cumulative volume fraction curve of metals $\mathrm{Cd}, \mathrm{Cu}, \mathrm{Pb}, \mathrm{Zn}$ and $\mathrm{Mn}$ in the two rainfall runoff on dates July 22, 2014 and September 28, 2014. Figure 1 shows the curve.

Gupta argue that, if the curve about quality of heavy metal load in rainfall runoff (i.e., $\mathrm{m}(\mathrm{v})$ ) locates in the upper part of the diagonal line, the initial scour effect is indicated ${ }^{[14]}$. According to Gupta's criteria, we can see from figure 1 that the $\mathrm{m}(\mathrm{v})$ curve on date July 22, 2014 exactly locates in the upper part of the diagonal line. Therefore, all the heavy metals in the samples collected on that date appear first flushing effect, especially $\mathrm{Cd}$ and $\mathrm{Pb}$. In contrast, the heavy metals in the samples collected on date September 28, 2014 does not has first flushing effect because the m(v) curve 
wandering around the diagonal. Because the rainfall runoff samples that are collected from the same Qingdao residential area, only the rain on July 22, 2014 is high intensity showers, but the rain on September 28, 2014 is light rain at the beginning and moderate rain lately. Therefore, whether first flushing effect of heavy metals in rainfall runoff appear is likely to be related to rainfall intensity, the conclusion is consistent with the research of Dafang Ful ${ }^{[13]}$.
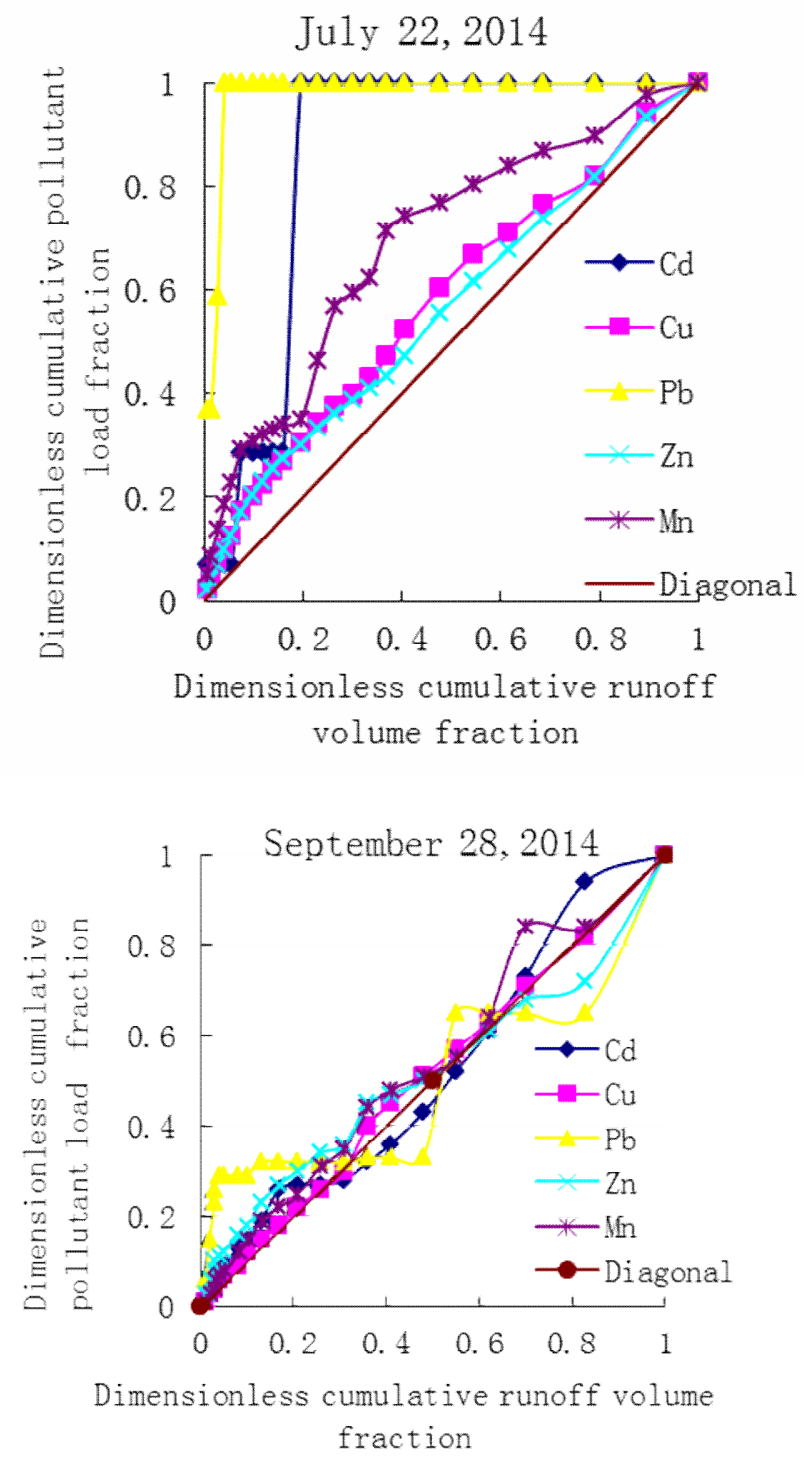

\section{Correlation of heavy metals in rainfall runoff}

Spearman correlation not only can be used to find linear relationship between parameters, but also can be adopted to find the monotonic nonlinear relationship. Besides, it does not need normality assumption on the analyzed data about variables ${ }^{[15,16]}$. Hence, in this paper, we adopt the Spearman correlation to study the relationship between the heavy metals in rainfall runoff of Qingdao residential area. Results are shown in table 2 and table 3. 
Table 2 Spearman's correlation coefficient of heavy metals in runoff collected on July 22, 2014

\begin{tabular}{llllll}
\hline $\begin{array}{l}\text { Heavy } \\
\text { metal }\end{array}$ & $\mathrm{Cd}$ & $\mathrm{Cu}$ & $\mathrm{Mn}$ & $\mathrm{Pb}$ & $\mathrm{Zn}$ \\
\hline $\mathrm{Cd}$ & 1 & & & & \\
$\mathrm{Cu}$ & 0.308 & 1 & & & \\
$\mathrm{Mn}$ & 0.251 & $0.504^{*}$ & 1 & & \\
$\mathrm{~Pb}$ & 0.21 & $0.842^{* *}$ & $0.502^{*}$ & 1 & \\
$\mathrm{Zn}$ & 0.1 & $0.727^{* *}$ & $0.539 * *$ & $0.580^{* *}$ & 1 \\
\hline
\end{tabular}

Note:"“** is the significant correlation(bilateral) when significance level equals 0.01 ,

$*$ is the significant correlation(bilateral) when significance level equals $0.05 \%$.

Table 3 Spearman's correlation coefficient of heavy metals in runoff collected on September 28,2014

\begin{tabular}{cccccc}
\hline $\begin{array}{r}\text { Heavy } \\
\text { metal }\end{array}$ & $\mathrm{Cd}$ & $\mathrm{Cu}$ & $\mathrm{Mn}$ & $\mathrm{Pb}$ & $\mathrm{Zn}$ \\
\hline $\mathrm{Cd}$ & 1 & & & & \\
$\mathrm{Cu}$ & $0.450^{*}$ & 1 & & & \\
$\mathrm{Mn}$ & -0.177 & 0.199 & 1 & & \\
$\mathrm{~Pb}$ & $0.539^{*}$ & $0.636^{* *}$ & 0.016 & 1 & \\
$\mathrm{Zn}$ & $0.524^{*}$ & $0.896^{* *}$ & 0.258 & $0.748^{* *}$ & 1 \\
\hline
\end{tabular}

Note:“*** is the significant correlation(bilateral) when significance level equals 0.01 ,

$*$ is the significant correlation(bilateral) when significance level equals 0.05 ".

From table 2, it can be seen that the correlation coefficient of $\mathrm{Cu}$ and $\mathrm{Pb}, \mathrm{Zn}$ on July 22, 2014 are larger than 0.7 when the significance level equals 0.01 . We can conclude that the heavy metals of $\mathrm{Cu}$ and $\mathrm{Pb}, \mathrm{Zn}$ have strong correlations. $\mathrm{Cd}, \mathrm{Mn}$ and other heavy metals have small correlation coefficient. Therefore, they are weakly correlated. Similar results can also be drawn according to table 3. Therefore, we can conclude that the heavy metals of $\mathrm{Cu}, \mathrm{Pb}$, and $\mathrm{Zn}$ in Qingdao residential area may largely be concomitant or from a same pollution source. However, $\mathrm{Cd}$ and $\mathrm{Mn}$ may have different pollution sources.

\section{CONCLUSIONS}

Experimental results show that the EMC of all heavy metals in rainfall runoff samples collected on date July 22, 2014 are in low level, therefor, the quality of rainfall runoff samples is good that no need to be controlled. In contrast, the EMC of heavy metals $\mathrm{Cd}$ in the samples collected on September 28, 2014 are in high level. Therefore, the quality of rainfall runoff samples on that date is poor so that need to be controlled.

The first flushing effect of heavy metals in rainfall runoff of July 22, 2014 is obvious. In contrast, the first flushing effect does not appear in the rainfall runoff of September 28, 2014. That results may closely relate to the intensity of these two raining.

The correlation between $\mathrm{Cu}, \mathrm{Pb}$ and $\mathrm{Zn}$ in rainfall runoff is strong, while the ones between $\mathrm{Cd}, \mathrm{Mn}$ and other heavy metals are weak. That may lead by the fact that $\mathrm{Cu}, \mathrm{Pb}$ and $\mathrm{Zn}$ may come from a similar pollution source, while $\mathrm{Cd}, \mathrm{Mn}$ and other heavy metals may come from another pollution source. 


\section{AUTHOR INTRODUCTION}

1、First author: Dr. Chunrong ZHANG, female, the main research is the environmental geology .E-mail:zcrsdust@126.com.

2、Corresponding author: Dr. Chunjin ZHANG, E-mail: zhangchjin@163.com.

\section{ACKNOWLEDGEMENT}

We are grateful to the Natural Science Fund of China (No.71303140, No.71403151, No.40901027), the Public welfare industry special funds for scientific research projects of Ministry of water resources (No.201301089) and the Natural Science Fund of Shandong Province (ZR2011DQ006, ZR2014DL006)

\section{REFERENCES}

[1]Sansalone JJ, Buchberger S G. Partitioning and first flush of metals in urban roadway storm water[J].Journal of EnvironmentalEngineering,1997,123(2):134-143.

[2]Dean C M, Sansalone JJ, CartledgeF K, et al. Influence of hydrology on rainfall-runoff metal elementspeciation[J].Journal ofEnvironmental Engineering,2005,131(4):632-642.

[3]Brezonik PL,Stadelmann TH.Analysis and predictive models of stormwater runoff volumes, loads, and pollutant concentrations from watersheds in the Twin Cities metropolitan area, Minnesota, USA[J].Water Resources, 2002, 36(7):1743-1757.

[4]Brown J N,PeakeBM. Sources of heavy metals and polycyclic aromatic hydrocarbons in urban stormwaterrunoff[J].Science of The Total Environment,2006,359(15):145-155

[5] Zhao J W, Shan B Q, Yin C Q. Pollutant loads of surface runoff in Wuhan City Zoo, an urbantourist area[J].Journal of Environmental Sciences,2007,19(4):464-468.

[6]Yangwei OU, Wei WANG, Fang-hua HAO, et a1. Pollution characterization of urban stormwater runoff on different underlying surface conditions[J]. China Environmental Science,2010,30(9):1249-1256. (in Chinese )

[7]Jing CHANG, Min LIU, Xianhua LI, et a1.Dissolved-particulatepartitioning of heavy metals in urban road runoff of Shanghai[J].Advances in Water Science,2009,20(5):714-720. (in Chinese )

[8] GB 7475-1987, Water quality-Determination of copper,zinc,lead and cadmium-Atomlc absorption spectrometry[S].Beijing: China standard press, 1987.

[9]GB11906-89, water quality-Determination of manganese-Potassium periodate spectrophotometric method[S].Beijing: China standard press, 1989.

[10] US EPA. Results of the nationwide urban runoff program [R].Washington, D C: U.S. Environmental Protection Agency, 1983.

[11]Jingjing ZHANG. Characteristics and Loading Estimates of Heavy Metals in Urban Rainfall Runoff[D]. Shanghai,East ChinaNormal University,2011.(in Chinese )

[12] Chunlin LI, Miao LIU, Yuanman HU,et a1.Analysis of first flush in rainfall runoff in Shenyang urban city[J].Acta Ecologica Sinica,2013,33(18):5952-5961. (in Chinese )

[13]Dafang FU, Junqing SHI, He LI. First flush analysis of heavy metals in expressway stormwater runoff[J]. Acta Scientiae Circum stantiae, ,2009.29 (8 ): 1672-1677. (in Chinese )

[14]Gupta K, Saul A J. Specific relationships forthe first flush load in combined sewer flows[J]. Water Research, 1996, 30 (5):1244-1252.

[15] Kaijun WANG, Tianqiang HUANG. Spearman rank correlation method based on trend $\operatorname{rank}[\mathrm{J}]$. Journal of Fujian Normal University(Natural Science Edition),2010, 26(1):38-41(in Chinese)

[16]Chunrong ZHANG, Zhenglong WU, Zongjun Gao, et a1. An analysis of impact of sediments on heavy metal enrichment in halobios of the Jiaozhou Bay[J],Geology in China,2012,39(4):1094-1098. (in Chinese ) 
International Forum on Energy, Environment Science and Materials (IFEESM 2015) 